\title{
Morphological and molecular differentiation of genus Corbicula suggests that two species are sympatrically distributed in Datong Lake in the Central Yangtze River Basin
}

\author{
Gui-Ping Wang ${ }^{1}$, Ting Zhang ${ }^{2}$, Jian Zhang ${ }^{1}$, De-Liang Li ${ }^{1 *}$ and Tiao-Yi Xiao'
}

\begin{abstract}
Background: White and purple color morphs of Corbicula have been identified all over the world. Previous studies suggested that the distinct difference of inner shell color, especially for sympatric individuals, derived mainly from their different genetic constitutions, not just environmental conditions. Two color morphs of Corbicula sympatric in Datong Lake were compared by both morphometric methods (shell length, shell height, and shell width) and genetic analysis (based on the mitochondrial cytochrome c oxidase subunit I gene COl-mtCOI) to explore their taxonomic relationship.
\end{abstract}

Results: Morphological analysis showed that there were no significant differences in the values of SH/SL, SW/SL, and SW/SH $(P>0.05)$ between the two color morphs. Meanwhile, there were no significant differences in measurable parameters among the four mitochondrial COI haplotypes (DT-1, DT-7, DT-19, and DT-31) $(P>0.05)$. The sequences of four haplotypes (DT-1, DT-7, DT-19, and DT-31) were identical to FW1, FW5, FW4, and FW3, respectively. Restriction fragment length polymorphism (RFLP) analysis showed that only the sequences of haplotype DT-7 could be digested by the restriction enzyme Sacl into two fragments with 200/500 bp. Haplotype DT-31 was found only in one individual (white morph), while each of the other three haplotypes shared with both two color morphs. Phylogenetic analysis demonstrated that the four haplotypes were subdivided into two divergent clades among freshwater clades, and haplotype DT-7 was a divergent sister taxon to the other three.

Conclusions: The results indicated that there were no distinct differences on morphological measures between the two color morphs, and each color morph shared with all four mitochondrial COI haplotypes. Two species (DT-7 referred as Corbicula fluminea and DT-1, DT-19, and DT-31 as Corbicula leana) might coexisted in the Datong Lake. Therefore, a comprehensive study combining nuclear and mitochondrial data along with biological information should be performed to confirm this assumption.

Keywords: Corbicula; Mitochondrial DNA COl; Phylogeny; Taxonomy

\footnotetext{
* Correspondence: lideliang80@aliyun.com

${ }^{1}$ College of Animal Science and Technology, Hunan Agricultural University,

Changsha 410128, China

Full list of author information is available at the end of the article
} 


\section{Background}

At the beginning of the 20th century, the modern native distribution of the genus Corbicula was confined in Asia, Africa, and Australia (Sousa et al. 2008). Corbicula has been dispersed worldwide rapidly by a combination of human and natural dispersion mechanisms (Araujo et al. 1993; Sousa et al. 2007). The first documented record of this genus outside its native range was in British Columbia in Canada in the 1920s (Counts 1981) and then rapidly spread throughout the continent. Afterwards, it was extended to South America in the 1970s (Lee et al. 2005; Pigneur et al. 2011) and Europe in the 1980s (Karatayev et al. 2007). Nowadays, the genus Corbicula has colonized almost all over the world (Renard et al. 2000; Pfenninger et al. 2002), which caused great ecological and economic impacts on introduced ecosystems in the invasive range. Although its invasion and rapid expansion have been of intensive research topic in freshwater ecology, the taxonomy and systematic status of freshwater clam Corbicula in its native range is still not clearly resolved (Park and Kim 2003). Several systematic uncertainties using molecular methods were clarified in the last decades, such as mitochondrial and nuclear marks (Hedtke et al. 2008; Komaru et al. 2012, 2013). However, it still remained confusing, mainly due to the polymorphism of the morphology, color of the shell, and complex reproduction modes. Therefore, more information on genus Corbicula in its native range will help solve this confusion.

In China, the genus Corbicula has been consumed as food since ancient times (Liao et al. 2013). In addition, it has also been explored for medicine with its pharmacological activity (Liu et al. 1979). However, the taxonomy and systematicness of the genus Corbicula were poorly understood. Seven species have been reported in China, including Corbicula fluminea, Corbicula fluminalis, Corbicula nitens, Corbicula aurea, Corbicula largillierti, Corbicula tenuis, and Corbicula scholastica, which were nominated mainly according to morphology (Tchange and Li 1965; Tchange et al. 1965; Huang and Cheng 2003). It is not clear if the same occurs just like in America and Europe.

The shell color of the genus Corbicula was highly polymorphic (Morton 1987). Generally, two different color morphs (white and purple) have been identified by significantly different dimension ratios (Hillis and Patton 1982; Tsoi et al. 1991; Park et al. 2002). These two morphs were usually nominated to be one (Morton 1986; Qiu et al. 2001) or two different species (Britton and Morton 1986; Morton 1987; Park et al. 2002). It was inferred that the differences between the shell color morphs of Corbicula mainly derived from their different genetic constitutions, not just environmental condition, especially for those sympatric individuals (Komura and Konishi 1999; Qiu et al. 2001; Park et al. 2002). In the present study, two shell color morphs (white and purple) of the genus Corbicula were discovered sympatrically in an aquaculture lake (Datong Lake) in the Central Yangtze River Basin. A combination of morphological methods (shell length (SL), shell height $(\mathrm{SH})$, and shell width $(\mathrm{SW})$ ) and genetic analysis (based on the mitochondrial cytochrome $c$ oxidase subunit I gene COI-mtCOI) were used to explore their systematic relationship. In addition, mtCOI sequences of individuals in the present study were compared with preexisting $\mathrm{mtCOI}$ sequences in China. The results will provide more valuable information to clarify the taxonomy and systematicness of the genus Corbicula.

\section{Methods}

\section{Study area and sampling}

Datong Lake was located at $29^{\circ} 05^{\prime} \sim 29^{\circ} 16^{\prime} \mathrm{N}$ and $112^{\circ}$ $26^{\prime} \sim 112^{\circ} 35^{\prime} \mathrm{E}$ in the nearly middle part of Hunan Province, China. It was separated from Dongting Lake since the reclamation of land in 1951 ( $\mathrm{Li}$ et al. 2012). Now, it covers a water surface area of $82.7 \mathrm{~km}^{2}$ (Figure 1). Sixty individuals of Corbicula clams were collected from the Datong Lake by using Peterson grab sampler in August 2012. All specimens were cleaned using a sieve with $0.5-\mathrm{mm}$ mesh and then placed immediately on ice for transportation.

\section{Morphological analysis and statistics}

For conventional morphometric analysis, three morphometric variables in 60 individuals were measured after wet weight (WW) was taken: shell length (the greatest anteroposterior dimension), shell height (the maximal dorsoventral dimension of the shell taken at the umbo), and shell width (the maximal width of the articulated paired valves) ( $\mathrm{Li}$ et al. 2013). The accuracy of weighing was $0.01 \mathrm{~g}$, and the morphological variable was $0.01 \mathrm{~mm}$ using a digital caliper.

All values were presented as means $\pm \mathrm{SE}$. All data were tested by using Shapiro-Wilk's $W$ test for normality, while using Levene's test for homogeneity of variances. Differences between two shell morphs were compared by $t$-test. Differences among haplotypes were analyzed using oneway ANOVA. All analyses were performed using Statistic 6.0 software (StatSoft, Inc., Tulsa, OK, USA), with $P<0.05$ considered statistically significant.

\section{Genetic analysis}

Genomic DNA was extracted from the mantle tissue of 60 individuals using TIANamp Marine Animals DNA Kit (Tiangen Biotech (Beijing) Co., Ltd., Beijing, China). A 710-bp fragment of the mitochondrial cytochrome $c$ oxidase subunit I gene (COI) was amplified using the primers LCO1490 (5'-GGTCAACAAATCATAAAGATAT TGG-3') and HCO2198 (5'-TAAACTTCAGGGTGACCA AAAAATCA-3') designed by Folmer et al. (1994). 


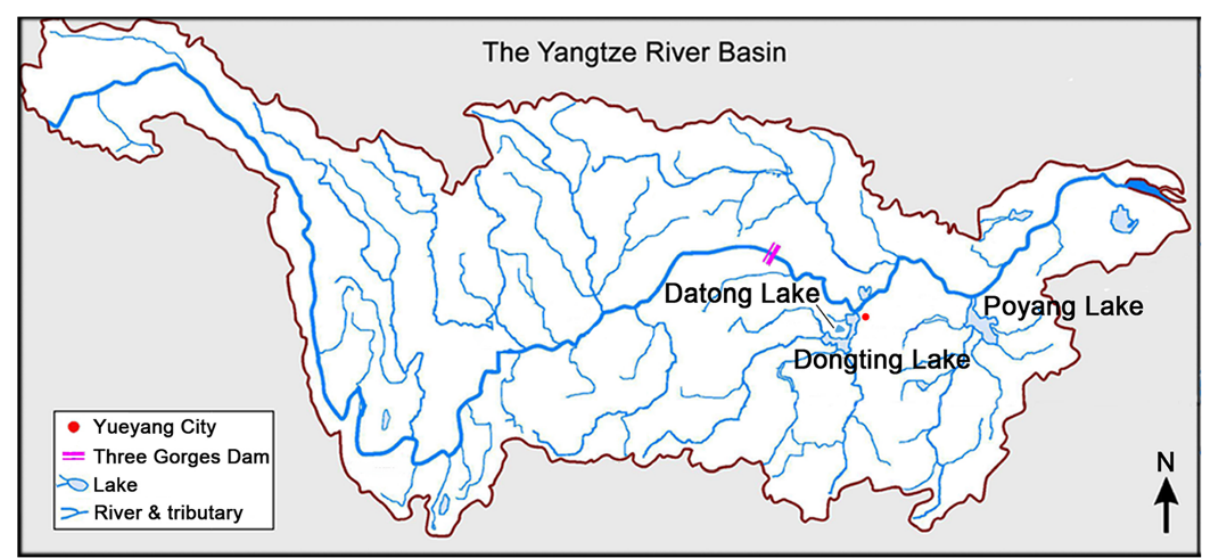

Figure 1 Location map of the study area.

Polymerase chain reaction (PCR) was performed in $25 \mu \mathrm{l}$, including $100 \mathrm{ng}$ of template DNA, $0.5 \mu \mathrm{M}$ of each primer, $2.5 \mu \mathrm{M}$ of each dNTP, $1.5 \mathrm{mM} \mathrm{MgCl} 2,1 \times$ Taq reaction buffer, $2.5 \mathrm{U}$ of Taq polymerase, and $\mathrm{dd}_{2} \mathrm{O}$. The PCR conditions were as follows: following initial denaturation of $5 \mathrm{~min}$ at $94^{\circ} \mathrm{C}, 35$ cycles of denaturation at $94^{\circ} \mathrm{C}$ for $60 \mathrm{~s}$, annealing at $52^{\circ} \mathrm{C}$ for $45 \mathrm{~s}$, and extension at $72^{\circ} \mathrm{C}$ for $1 \mathrm{~min}$, followed by a final extension for $5 \mathrm{~min}$ at $72^{\circ} \mathrm{C}$ were done. A negative control reaction (no template DNA) was performed alongside the experimental PCR. The PCR products were purified using a TIANgel Midi Purification Kit (Tiangen Biotech (Beijing) Co., Ltd., Beijing, China) and sequenced with each of the same primers by Sangon Biotech (Shanghai) Co., Ltd. (Shanghai, China). In order to avoid erroneous sequence determination at the $5{ }^{\prime}$ - and $3{ }^{\prime}$-terminal regions, only a 614-bp fragment was selected for further phylogenetic analysis. The PCR products of the four haplotypes were digested with a restriction enzyme $S a c I$. The digestion reaction was performed according to the procedures provided by the enzyme supplier (Fermentas Inc., Burlington, Ontario, Canada).

The haplotype sequences in the Datong Lake were identified by comparing with those from previously published studies on Corbicula using the BLAST program (Altschul et al. 1997): FW1 (GenBank, AF196269), FW2 (AF457989), FW3 (AF457990), FW5 (AF196268), FW11 (AF457994), FW12 (AF457995), FW13 (AF457999), and FW4 (AF269096-8). The sequences were visualized and aligned using BioEdit 7.0.5.3 software. Haplotypes were determined using the DnaSP program (Rozas et al. 2003). MEGA version 5.1 software was employed for the construction of the neighbor-joining (NJ) tree and maximum likelihood (ML) tree, estimating genetic distances according to Tamura (1992) 3' parameters method. Two published sequences of Zebra mussels (U47648 and
U47652) were designed as outgroups. The reliability of nodes on trees was obtained using bootstrap analysis with 1,000 replicates (Felsenstein 1985; Sousa et al. 2007).

\section{Results}

\section{Shell morphology}

Two distinct color forms were recognized (white or purple morph) (Figure 2). Both of the two shell color morphs shared more or less centrally located umbo, glossy periostracum, prominent and raised sculpture, and regular concentric ribs. The purple morph with purple internal and dark green external was featured whitish from the pallia line to the umbo. The white morph, described as having white internal and light green external, was also characterized by the purple flashes along its anterior and posterior lateral teeth.

WW, SL, SH, and SW were not significantly different between the two color morphs $(P>0.05)$. There were no significant differences among four haplotypes for WW, SL, SH, and SW and three ratios of SH/SL, SW/SL, and SW/SH $(P>0.05)$ (Table 1) either. The SW/SL value of DT-7 $(0.68 \pm 0.01, N=16)$ was much larger than those of DT-1, DT-19 and DT-31 $(0.65 \pm 0.01, N=44)(P<0.05)$, whereas $\mathrm{SH} / \mathrm{SL}$ and $\mathrm{SW} / \mathrm{SH}$ of the two groups were similar.

\section{Genetic variability}

Among the 60 individuals, four haplotypes (DT-1, DT-7, DT-19, and DT-31) were identified. In addition, haplotype DT-31 was found only in one individual (white morph); the other three haplotypes (DT-1, DT-7, and DT-19) were discovered to have both white and purple morphs. Thirtyeight of the 60 sequences corresponded to the haplotype DT-1, and 16, 5, and 1 represented the other three haplotypes (Figure 3). Alignment of the identified sequences revealed that the four haplotypes were resolved differing by one point ( $0.2 \%$ divergence) to 16 sites ( $2.6 \%$ divergence). 


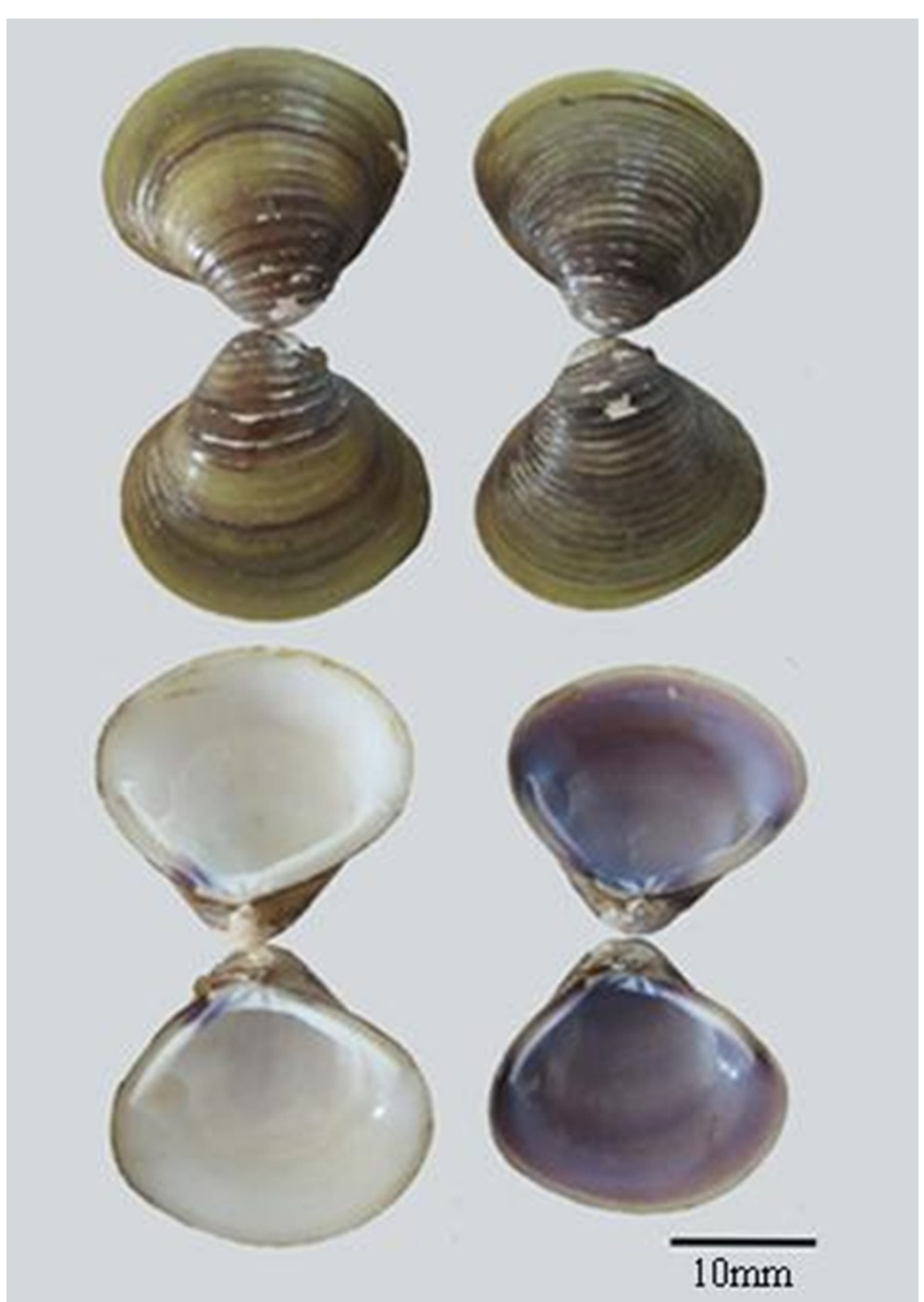

Figure 2 Shell morphology of two color morphs of Corbicula clams in Datong Lake.

No novel haplotype of Corbicula was discovered in the present study, and the sequences of DT-1, DT-7, DT-19, and DT-31 were identical to FW1, FW5, FW4, and FW3 that were found in Asia, respectively (Park and Kim 2003). Restriction fragment length polymorphism (RFLP) analysis of the four haplotypes showed that only the 710-bp fragment of haplotype DT-7 was digested by the one-site restriction enzyme SacI and provided two fragments with 200/500 bp.
Phylogenic trees constructed by NJ and MP methods showed similar tree topologies (Figure 4). The results demonstrated that the analyzed haplotypes were subdivided into two divergent clades-estuarine (composed exclusively of brackish members) and freshwater (exclusively comprising freshwater members) clades. Among the freshwater Corbicula members, haplotype DT-7 and FW5 occupied a well-supported basal position rather than the remaining three (Figure 4).

Table 1 Morphometric data of the shells of Corbicula clams from Datong Lake, with mitochondrial COI haplotypes

\begin{tabular}{lllllllll}
\hline Haplotypes & Number & WW & SL & SH & SW & SH/SL & SW/SL & SW/SH \\
\hline DT-1 & 38 & $2.93 \pm 0.23$ & $19.39 \pm 0.48$ & $18.26 \pm 0.43$ & $12.61 \pm 0.27$ & $0.94 \pm 0.01$ & $0.65 \pm 0.01$ & $0.69 \pm 0.01$ \\
DT-7 & 16 & $2.78 \pm 0.29$ & $18.57 \pm 0.69$ & $17.88 \pm 0.65$ & $12.53 \pm 0.39$ & $0.96 \pm 0.01$ & $0.68 \pm 0.01$ & $0.70 \pm 0.01$ \\
DT-19 & 5 & $2.93 \pm 0.62$ & $18.88 \pm 1.75$ & $18.01 \pm 1.56$ & $12.28 \pm 1.09$ & $0.96 \pm 0.02$ & $0.65 \pm 0.02$ & $0.68 \pm 0.01$ \\
DT-31 & 1 & 2.90 & 18.98 & 18.37 & 12.27 & 0.97 & 0.65 & 0.67 \\
\hline
\end{tabular}




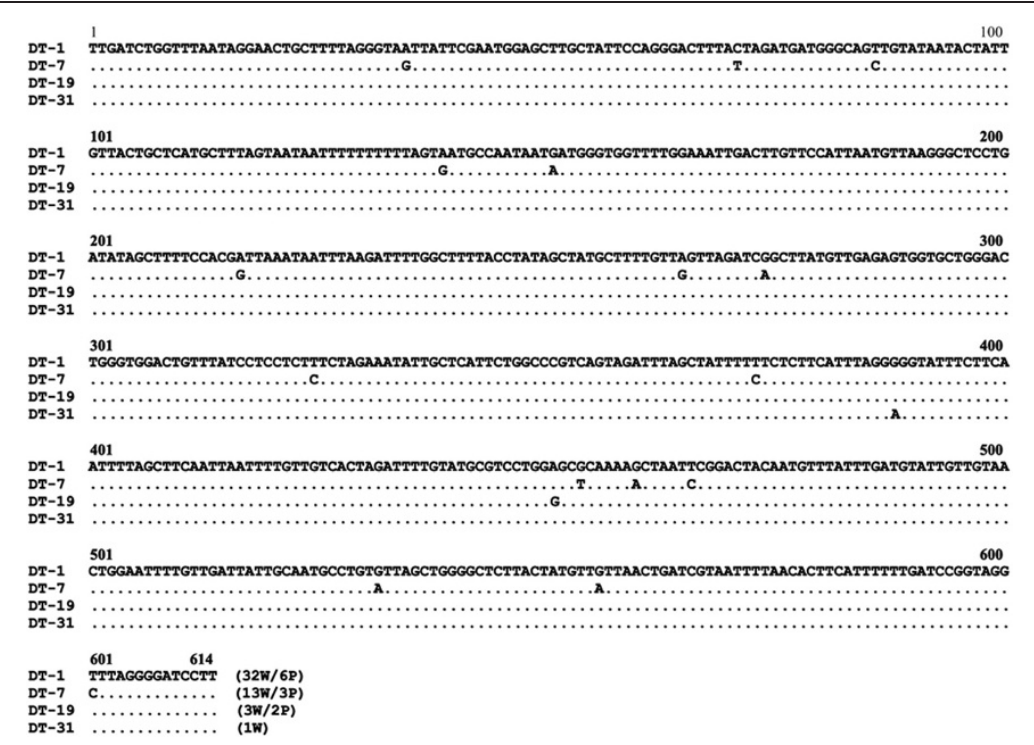

Figure 3 Alignment of four haplotypes and variable sites in partial mtDNA COI sequence of Corbicula. Of the 60 analyzed sequences, 32 white morphs and 6 purple morphs correspond to DT-1, 13 white and 3 purple to DT-7, 3 white and 2 purple to DT-19, and 1 white to DT-31.

\section{Discussion}

Two shell color morphs of Corbicula clam have already been described from a number of regional populations, such as North America (Hillis and Patton 1982; Siripattrawan et al. 2000), Japan (Houki et al. 2011), Thailand (Kijviriya et al. 1991), Hong Kong (Tsoi et al. 1991), Taiwan (Komura and Konishi 1999), and China (Qiu et al. 2001). It was inferred that not only environmental condition but also the different genetic constitutions resulted in the differences between the two color morphs (Qiu et al. 2001), especially for those sympatric individuals. Most researchers have reached an agreement that the two morphotypes should be relegated to two separate species, for C. fluminea (white morph) and C. leana (purple morph) (Choe et al. 1999; Kwon et al. 2001; Park et al. 2002). In Datong Lake, two sympatric shell color morphs were generally to be identified as C. fluminea on account of their similar external shell morphology ( $\mathrm{Li}$ et al. 2011, 2013). Similar results of C. fluminea have also been reported in Sichuan Province, China (Qiu et al. 2001). Morphological analysis in the present study further supported that there were no significant differences between the two color morphs except for their different internal color in Datong Lake. This was inconsistent with that in Sichuan Province (Qiu et al. 2001), in which the three ratios of SW/SL, SW/SH, and $\mathrm{SW} /(\mathrm{SL}+\mathrm{SH}+\mathrm{SW})$ were significantly larger in white morph than in purple morph. Therefore, these results supported the assumption that the origin of differences between two color morphs should have been derived from genetic constitutions.
DNA sequencing analysis revealed four distinct haplotypes in 60 individuals in Datong Lake. No novel haplotype was discovered, comparing with those available sequences in Asia including the two largest freshwater lakes of China (Poyang Lake and Dongting Lake) (Park and Kim 2003). Because Datong Lake was once part of Dongting Lake 60 years ago, the results may suggest that at least four haplotypes coexisted in the Dongting Lake not just three haplotypes reported previously (Park and Kim 2003). Nowadays, eight haplotypes have been identified, including FW1/DT-1, FW2, FW3/DT-31, FW4/DT19, FW5/DT-7, FW11, FW12, and FW13. Therefore, more extensive samplings especially for species in Qingshan Lake which has novel haplotypes (FW11, FW12, and FW13) should be carried out to clarify the taxonomy and phylogeny of Corbicula in China. In addition, three major haplotypes (DT-1, DT-7, and DT-19) each was shared with both two color morphs. Thus, more individuals in Datong Lake should be analyzed to make sure whether it was true for DT-31. The genetic analysis based on phylogenic trees strongly supported the sister status of the estuarine clade to all its freshwater congeners, which was consistent with previous results (Park and Kim 2003; Pigneur et al. 2011). Among the freshwater clades, haplotype DT-7 was a divergent sister taxon to the other three, obviously supported by maximum bootstrap values (100\%). In the present study, both of the haplotype DT-7 and FW5 (referred as C. leana in Japan) shared identical sequence, similar RFLP result, and robust support (a bootstrapping value of 100\%). Hence, the individuals with haplotype DT-7 could be assigned as C. leana, which was one of the most 

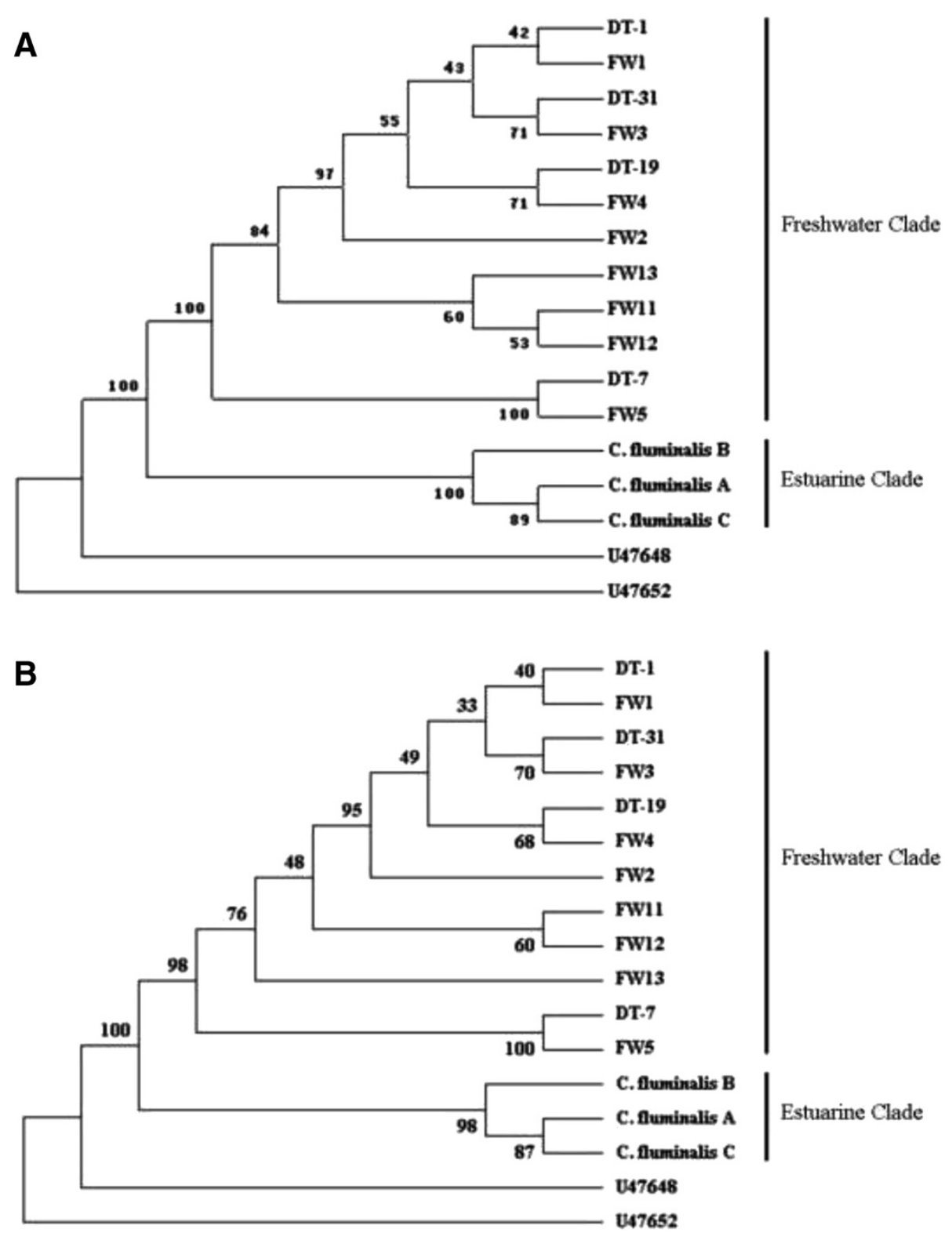

Figure 4 Phylogenic trees constructed by $\mathbf{N J}(\mathbf{A})$ and $\mathbf{M L}(\mathbf{B})$ methods. The construction of the trees was based on a 614-bp fragment of the mitochondrial gene COI dataset. Sequences of U47648 and U47652 were used as outgroups. Bootstrap proportions and posterior probabilities are shown close to the nodes.

common recorded freshwater system members in Asia. Accordingly, the individuals with haplotypes DT-1, DT-19, and DT-31 could be described as C. fluminea (FW1, FW3, and FW4 were referred to as C. fluminea). This assumption would also be supported by the minor significant differences in shell morphological characters between DT-7 and the group of haplotypes DT-1, DT-19, and DT-31.

Therefore, all results in the present study showed that two species (C. leana and C. fluminea) of genus Corbicula may coexisted in Datong Lake, and each species shared both two color morphs. This was significantly inconsistent with the previous results that the two morphotypes should be relegated to two separate species, for white morph $C$. fluminea and purple morph C. leana (Choe et al. 1999; Kwon et al. 2001; Park et al. 2002), or only to be identified as C. fluminea (Qiu et al. 2001; Li et al. 2011). However, this assumption should be confirmed further. As it was reported, most phylogenetic studies on Corbicula based on mitochondrial data could lead to inaccurate species delimitation because of mitochondrial/morphotype-nuclear mismatch (Pigneur et al. 2011). In addition, the special androgenesis and hermaphrodite characteristics that were recorded in most Corbicula species made the delineation of Corbicula even more complicated. Hence, a comprehensive 
study combining nuclear and mitochondrial data, along with morphology and biological information will do help to distinguish the taxonomy and systematic status of the two color morphs in further studies.

\section{Conclusions}

Two color morphs (white and purple) of Corbicula sympatric in Datong Lake were compared by morphometric methods and genetic analysis to explore their taxonomic relationship. The results showed that there were no distinct differences on morphological measures in the aspects of the two color morphs and the four mitochondrial COI haplotypes (DT-1, DT-7, DT-19, and DT-31). Each color morph was shared by all four mitochondrial COI haplotypes. Phylogenetic analysis demonstrated that the four haplotypes were subdivided into two divergent clades among freshwater clades, and haplotype DT-7 was a divergent sister taxon to the other three. Thus, two species (DT-7 as C. leana and DT-1, DT-19, and DT-31 as C. fluminea) may coexisted in Datong Lake. However, this assumption should be confirmed further because of the potential inaccurate species delimitation resulting from the mitochondrial/morphotype-nuclear mismatch in Corbicula genus.

\section{Competing interests}

The authors declare that they have no competing interests.

\section{Authors' contributions}

This study was performed in collaboration among all authors. GPW carried out the experiment, participated in the statistical analysis, and drafted the manuscript. TZ provided expertise in drafting, reviewing, and revising the manuscript for intellectual content. JZ participated in collecting the samples of Corbicula. DLL conceived of the study, designed the experiment, and drafted the manuscript. TYX provided purely technical help. All authors read and approved the final manuscript.

\section{Acknowledgements}

This study was supported by the National Natural Science Foundation of China (31100282) and Special Fund for Agro-Scientific Research in the Public Interest (201303056-7).

\section{Author details}

${ }^{1}$ College of Animal Science and Technology, Hunan Agricultural University, Changsha 410128, China. ${ }^{2}$ Centre for Environment and Water Resources, College of Chemistry and Chemical Engineering, Central South University, Changsha 410083, China.

Received: 26 May 2014 Accepted: 2 September 2014

Published online: 11 September 2014

\section{References}

Altschul SF, Madden TL, Schäffer AA, Zhang J, Zhang Z, Miller W, Lipman DJ (1997) Gappeb BLAST and PSI-BLAST: a new generation of protein database search programs. Nucleic Acids Res 25:3389-3402

Araujo R, Moreno D, Ramos MA (1993) The Asiatic clam Corbicula fluminea (Müller, 1774) (Bivalvia: Corbiculidae) in Europe. Am Malac Bull 10:39-49

Britton JC, Morton BS (1986) Polymorphism in Corbicula fluminea (Bivalvia: Corbiculidae) from North America. Malacol Rev 19:1-43

Choe BL, Park MS, Jeon LG, Park SR, Kim HT (1999) Commercial mollusks from the freshwater and continental shelf in Korea. National Fisheries Research and Development Institute. Kudu Publishing Co., Pusan

Counts CL (1981) Corbicula fluminea (Bivalvia: Corbiculidae) in British Columbia. Nautilus 95:12-13
Felsenstein J (1985) Confidence limits on phylogenies: an approach using the bootstrap. Evolution 39:783-791

Folmer O, Black M, Hoeh E, Lutz R, Vrijenhoek R (1994) DNA primers for amplification of mitochondrial cytochrome $c$ oxidase subunit I from diverse metazoan invertebrates. Mol Mar Biol Biotechnol 3:294-299

Hedtke SM, Stanger-Hall K, Baker RJ, Hillis DM (2008) All-male asexuality: origin and maintenance of androgenesis in the Asian clam Corbicula. Evolution 62-5:1119-1136

Hillis DM, Patton JC (1982) Morphological and electrophoretic evidence for two species of Corbicula (Bivalvia: Corbiculidae) in North America. Am Midl Nat 108:74-80

Houki SJ, Yamada MY, Honda T, Komaru A (2011) Origin and possible role of males in hermaphroditic androgenetic Corbicula clams. Zoolog Sci 28:526-531

Huang BY, Cheng LY (2003) Bivalves in the Zhengyangguan part of the Huai River, Shou County, Anhui Province. Chin J Zool 23:80-85

Karatayev AY, Padilla DK, Minchin D, Boltovskoy D, Burlakova LE (2007) Changes in global economies and trade: the potential spread of exotic freshwater bivalves. Biol Invasions 9:161-180

Kijviriya V, Upatham ES, Woodruff DS (1991) Genetic studies of Asian clams, Corbicula, in Thailand: allozymes of 21 nominal species are identical. Am Malac Bull 8:97-106

Komaru A, Houki SJ, Yamada M, Miyake T, Obata M, Kawamura K (2012) $28 \mathrm{~S}$ rDNA haplotypes of males are distinct from those of androgenetic hermaphrodites in the clam Corbicula leana. Dev Genes Evol 222:181-187

Komaru A, Yamada M, Houki SJ (2013) Relationship between two androgenetic clam species, Corbicula leana and Corbicula fluminea, inferred from mitochondrial cytochrome b and nuclear $28 \mathrm{~S}$ rRNA markers. Zoolog Sci 30:360-365

Komura A, Konishi K (1999) Non-reduced spermatozoa in three color types of the freshwater clam Corbicula fluminea in Taiwan. Zoolog Sci 16:105-108

Kwon OK, Min DK, Lee JR, Lee JS, Je JG, Choe BL (2001) Korean Mollusks with Color Illustration. Hanguel Publishing Co., Pusan

Lee T, Siripattrawan S, Ituarte CF, Foighil DÓ (2005) Invasion of the clonal clam: Corbicula lineages in the New World. Am Malac Bull 20:113-122

Li DL, Zhang T, Yu JB, Mao XW, Wang HQ, Chen K, Liu AM, Li ZJ, Xiao TY (2011) Temporal and spatial distributional patterns of mollusca in a typical aquaculture lake—Datong Lake. Acta Hydrobiol Sin 35:946-954

Li DL, Zhang T, Xiao TY, Yu JB, Mao XW, Wang HQ, Chen KJ, Liu AM, Li ZJ (2012) Phytoplankton's community structure and its relationships with environmental factors in an aquaculture lake, Datong Lake of China. Chin J Appl Ecol 23:2107-2113

Li DL, Zhang T, Xiao TY, Gong WB, Xie J, Li ZJ, Liu AM (2013) Standing crops and temporal-spatial distribution of Corbicula fluminea (Müller, 1774) in Lake Datong, Hunan Province. J Lake Sci 25:743-748

Liao NB, Chen SG, Ye XQ, Zhong JJ, Wu N, Dong SL, Yang B, Liu DH (2013) Antioxidant and anti-tumor activity of a polysaccharide from freshwater clam, Corbicula fluminea. Food Funct 4:539-548

Liu YY, Zhang WZ, Wang YX, Wang EY (1979) Freshwater Mollusk Economic Fauna of China. Science Press, Beijing

Morton BS (1986) Corbicula in Asia-an updated synthesis. Am Malacol Bull Spec Ed 2:113-124

Morton BS (1987) Polymorphism in Corbicula fluminea (Bivalvia: Corbiculidae) from Hong Kong. Malac Rev 20:105-127

Park JK, Kim W (2003) Two Corbicula (Corbiculidae: Bivalvia) mitochondrial lineages are widely distributed in Asian freshwater environment. Mol Phylogenet Evol 29:529-539

Park JK, Lee JS, Kim W (2002) A single mitochondrial lineage is shared by morphologically and allozymatically distinct freshwater Corbicula clones. Mol Cells 14:318-322

Pfenninger M, Reinhardt F, Streit B (2002) Evidence for cryptic hybridization between different evolutionary lineages of the invasive clam genus Corbicula (Veneroida, Bivalvia). J Evol Biol 15:818-829

Pigneur LM, Marescaux J, Roland K, Etoundi E, Descy JP, Doninck KV (2011) Phylogeny and androgenesis in the invasive Corbicula clams (Bivalvia, Corbiculidae) in Western Europe. BMC Evol Biol 11:147

Qiu AD, Shi AJ, Komaru A (2001) Yellow and brown shell color morphs of Corbicula fluminea (Bivalvia, Corbiculidae) from Sichuan Province, China, are triploids and tetraploids. J Shellfish Res 20:323-328

Renard E, Bachmann V, Cariou ML, Moreteau JC (2000) Morphological and molecular differentiation of invasive freshwater species of the genus 
Corbicula (Bivalvia, Corbiculidae) suggest the presence of three taxa in French rivers. Mol Ecol 9:2009-2016

Rozas J, Sanchez-DelBarrio JC, Messeguer X, Rozas R (2003) DnaSP, DNA polymorphism analyses by the coalescent and other methods. Bioinformatics 19:2496-2497

Siripattrawan S, Park JK, Foighil DÓ (2000) Two lineages of the introduced Asian freshwater clam Corbicula occur in North American. J Moll Stud 66:423-429

Sousa R, Freire R, Rufino M, Mendez J, Gaspar M, Antunes C, Guilhermino L (2007)

Genetic and shell morphological variability of the invasive bivalve Corbicula fluminea (Müller, 1774) in two Portuguese estuaries. Estuar Coast Shelf Sci 74:166-174

Sousa R, Antunes C, Guilhermino L (2008) Ecology of the invasive Asian clam Corbicula fluminea (Müller, 1774) in aquatic ecosystems: an overview. Ann Limnol Int J Lim 44:85-94

Tamura K (1992) The rate and pattern of nucleotide substitution in Drosophila mitochondrial DNA. Mol Biol Evol 9:814-825

Tchange S, Li SC (1965) Bivalves (Mollusca) of the Poyang Lake and surrounding waters, Kiangsi Province, China, with description of a new species. Acta Zool Sin 17:309-317

Tchange S, Li SC, Liu YY (1965) Bivalves (Mollusca) of Tung-ting Lake and its surrounding waters, Hunan Province, China. Acta Zool Sin 17:197-217

Tsoi SCM, Lee SC, Wu WL, Morton B (1991) Genetic variation in Corbicula fluminea (Bivalvia: Corbiculidae) from Hong Kong. Malac Rev 24:25-34

doi:10.1186/s40555-014-0064-9

Cite this article as: Wang et al:: Morphological and molecular differentiation of genus Corbicula suggests that two species are sympatrically distributed in Datong Lake in the Central Yangtze River Basin. Zoological Studies 2014 53:64.

\section{Submit your manuscript to a SpringerOpen ${ }^{\circ}$ journal and benefit from:}

- Convenient online submission

- Rigorous peer review

- Immediate publication on acceptance

- Open access: articles freely available online

- High visibility within the field

- Retaining the copyright to your article 